\title{
Connectivity between land, water, and people: integrating process concepts and assessment evidence across disciplines for co-design of soil erosion solutions
}

\author{
W.H. Blake ${ }^{1}$, Claire Kelly ${ }^{2}$, M Wynants ${ }^{2}$, Aloyce Patrick ${ }^{3}$, Shaun Lewin ${ }^{1}$, Joseph Lawson ${ }^{4}$, \\ Emmanuel Nasolwa ${ }^{3}$, Annabel Page ${ }^{1}$, Mona Nasseri ${ }^{5}$, Carey Marks ${ }^{6}$, David Gilvear ${ }^{1}$, \\ Kelvin Mtei $^{3}$, Linus Munishi ${ }^{3}$, and Patrick Ndakidemi ${ }^{3}$ \\ ${ }^{1}$ Plymouth University \\ ${ }^{2}$ University of Plymouth \\ ${ }^{3}$ Nelson Mandela African Institute of Science and Technology \\ ${ }^{4}$ Arhwithrans Surveys Ltd \\ ${ }^{5}$ Schumacher College \\ ${ }^{6}$ Scarlet Design
}

April 28, 2020

\begin{abstract}
Soil resources in East Africa are being rapidly depleted by erosion, threatening food-, water- and livelihood security in the region. Here we demonstrate how integration of evidence from natural and social sciences has supported community-led change in land management in an agro-pastoral community in northern Tanzania impacted by soil erosion. Drone survey data and geospatial analysis of erosion extent and risk, supported by communication of 'process' and 'structural' hydrological connectivity, was integrated with local environmental knowledge within participatory community workshops. Rill density data were compared between cultivated plots that had been converted from pastoral land recently and more established plots where slow-forming terrace boundaries were more established. Slope length and connectivity between plots were key factors in development of rill networks. At the two extremes, recently converted land had a rill density ca 14 times greater than equivalent established slow forming terraces. Direction of cultivation, regardless of plot boundary orientation with contours, also enhanced rill development. Evidence of this critical time window of hillslope-scale rill erosion risk during early phases of slow-forming terrace development successfully underpinned and catalysed a community-led tree planting and grass seed sowing programme to mitigate soil erosion by water. This was grounded in an implicit community understanding of the need for effective governance mechanisms at both community and District levels, to enable community-led actions to be implemented effectively. The study demonstrates the wide-reaching impact of integrated and interdisciplinary 'upslope-downslope' thinking to tackle global soil erosion challenges.
\end{abstract}

Keywords: land degradation, agro-pastoral, drought, erosion, co-design

\section{Introduction}

\subsection{Soil erosion challenges in East Africa}

The East African region harbours rich natural resources that exist in sharp contrast across the landscape (Veldhuis et al., 2019). These areas are populated with varied human and livestock densities and while the landscape provides many ecosystem services, provision is hampered by human activity and land degradation that include soil erosion. Climate changes, ecosystem degradation, biodiversity losses and sociopolitical 
pressures all impact development, conservation and livelihoods of socio-ecological systems of which majority of communities rely on across the region.

Soil resources in East Africa are being rapidly depleted by erosion, threatening food-, water- and livelihood security in the region (Wynants et al. 2019; Cobo et al., 2010; Oldeman, 1991). While soil and land resources are progressively being depleted the population, with associated needs for livelihoods, food, fibre, and other resources is expanding (FAO, 2019). Agricultural intensification and economic diversification are hampered by a lack of available knowledge, skills and agricultural technology (Korotayev and Zinkina, 2015) and as a result, an increasing number of farmers are pushed to seek more land to establish agricultural operations, causing a marked shift from naturally vegetated landscapes towards agricultural landscapes (Jayne et al., 2014; Odgaard, 2002). Policies of sedentarisation, privatisation and confinement within administrative boundaries have impeded the mobility of previously nomadic pastoralist communities (Homewood et al., 2004). Moreover, pastoral communities are also experiencing internal pressures due to higher livestock and other inequality existing among gender and other community social groups, rapid changes in herd sizes and stocking densities (both expansion and contraction), shifts towards the need for external employment opportunities and increased competition over grazing resources (Rabinovich et al., 2019; Rufino et al., 2013). A combination of all these and other factors have led to a tripling of the livestock numbers in the last 50 years (FAO, 2019) with increasing the local densities of domestic grazers in many areas, leading to overgrazing and trampling of the soil (Little, 1996; Ruttan and Borgerhoff Mulder, 1999). Furthermore, the high reliance on natural vegetation as a source of fuel, construction materials and fodder in both the urban and rural populations is resulting in substantial exploitation pressures on forests and woodlands (Hiemstra-van der Horst and Hovorka, 2009). The conjunction of these multiple pressures has increased rates of surface runoff, soil erosion, gully incision and downstream sediment transport (Blake et al., 2018; Vanmaercke et al., 2014; Wynants et al., 2020). Furthermore, these processes are potentially amplified by natural rainfall variations (Ngecu and Mathu, 1999) and projected increases in extreme climatic events e.g. drought followed by extreme rainfall (Nearing et al., 2004). East-Africa's environments/ecosystems are highly dynamic in both time and space, posing substantial challenges to the communities that are dependent on them and the development of sustainable land management plans.

\subsection{Integration of hydrological and socio-economic connectivity concepts in land management plans}

Interventions to reduce overland flow and soil erosion by water range in spatial scale from the farm plot to hillslope and catchment level. The conservation agriculture (CA) approach (International Institute of Rural Reconstruction and African Conservation Tillage Network., 2005; Kassam et al., 2019) centres around the mitigation of on-site soil erosion effects on cultivated land, where soil conserving cropping practices help reduce erosion and water run-off. Three key interventions that are essential to CA, however, are applied to different extents and site-specific contexts. First, minimum or no-tillage practice reduces soil disturbance, supports higher infiltration capacity and reduces the risk of overland flow. Second, permanent cover of soil by vegetation and/or use of crop residues as mulch reduces rain splash and compaction/crusting of the soil surface. Third, crop rotations and intercropping, even though their main aim is to increase soil fertility and yield, consequentially improve soil organic matter content, increase soil aggregate stability and hence help reduce erodibility. Edge-of-plot attenuation features (e.g. vegetative barriers, ditches, bunds, buffers) mitigate both on-site impacts, through retention and capture of soil and nutrients in the farm, and off-site impacts, by impeding downslope water flow. East-African hillslope farms are often cultivated under slow-forming terraces (Kagabo et al., 2013), where soil eroded up the plot congregates at the plot boundary, thereby reducing hillslope gradient. Downslope catchment measures include the use of check dams or other flow retardants in gullies and incised channels to slow down the water discharge response to the drainage network, recue channel incision and stimulate sediment deposition. These offer win-win outcomes of landscape restoration and enhanced resilience to future climate threats such as extreme rainfall and drought. Successful implementation of these multi-scalar intervention opportunities can only be realised with a thorough and nuanced understanding of community-specific needs and priorities, as well as wider political and economic contexts, all set within a deep understanding of landscape hydrological processes and concepts in both 'structural' and 'process' connectivity (Bracken et al., 2013). In brief, the term 'structural 
connectivity' has been used to describe the distribution of landscape units and features e.g. topographic controlled, flow convergence lines, gully or track networks that physically facilitate water and sediment transfers from hillslope to channel. Structural connectivity approaches are limited to supporting inferences of potential hydrological connectivity should overland flow be generated. In this regard, the concept of 'process connectivity' has greater relevance to tackling overland flow generation and soil erosion by water. This concept encompasses the actual processes that operate to produce fluxes of water and sediment and capture the evolutionary dynamics of how hydrological systems function (Bracken et al., 2013). For example, soil crusting reduces infiltration capacity leading to infiltration excess overland flow which converges to form and feed rill and gully network structures. The concept refers to the activation of the potential pathways described within a structural connectivity framework, which is generally highly temporally discrete. To date, however, process and functional connectivity concepts in hydrology have not directly accounted for the human dimension in land management decision making an impact of soil hydrology nor the maturity of land conversion features that might over time increase soil retention efficacy. Furthermore, in the East African context, connectivity within hillslopes and river basins is dynamic in both space and time (Wynants et al., 2020) with marked changes in connectivity due to rainfall variations, river networks, rapid land use change and positive feedback of gully incision and channel network expansion over decadal scales - hydro-geomorphic processes that are still not well understood or quantified.

The complex spatial and temporal dynamics of overland flow, soil erosion and sediment conveyance downstream can be better understood by the scientific community within the framework of hydrological connectivity. However, stakeholders also have context-specific local in-depth knowledge of landscape processes, albeit generally through an agro-pastoral practitioner lens that encompasses social and economic facets (Wynants et al. 2019). As such, integrating scientific findings into locally led land management plans presents a challenge/barrier to research impact. Co-design of land management policy which integrates local socio-economic and environmental knowledge and is tailored to the needs of specific communities is a credible pathway to sustainable change.

Participatory research in this context aims to evaluate not only the key environmental challenges affecting communities but also, and more critically, to understand the socio-ecological connectivity (Berkes et al., 2000) between these environmental challenges and their integration in socio-economic processes at multiple spatial levels and temporal scales. Prior work has shown that understanding the linkages is vital to enable sustainable and equitable change and break the cycle of declining resilience to soil erosion (Pretty, 1995). In this East African context, soil erosion is a civic as well as a practical problem. Roads, trackways and community spaces are all exposed soil surfaces and thus the problem is not limited to those engaged in agriculture alone; it is a challenge for the whole community. From this perspective, every community member has a stake in contributing to the effort to find sustainable solutions; and every community member has an opportunity to take action to effect real and lasting change. Co-designing mitigation strategies with communities ensures that potential solutions are relevant, applicable and achievable, particularly where alternative livelihood strategies to support pathways to sustained change are applied. This is exemplified by Reed et al.'s 'bottom-up' participatory principles (Reed et al., 2017) where community-led planning is guided by the local ambitions of stakeholders alongside the strategic objectives of external agencies and state authorities, leading to equitable solutions with much wider community 'buy-in' than those designed through top-down and non-participatory mechanisms (Pretty, 2003).

\section{$1.3 \mathrm{Aim}$}

This contribution demonstrates how an established interdisciplinary participatory approach (Figure 1) supported community-led change in land management in an East African agro-pastoral community. It explores how integration of drone survey data and geospatial analysis of erosion extent and risk, supported by communication of 'process' and 'structural' hydrological connectivity, with community participation successfully underpinned and catalysed a community-led tree planting and grass seed sowing programme to mitigate soil erosion by water.

$<<$ INSERT FIGURE $1>>$ 
Figure 1: Interdisciplinary approach to linking evidence into action (Blake et al., 2018)

\section{Materials and methods}

\subsection{Study area: Emaerete sub-catchment}

The study site (Figure 1) is located in the Monduli Highland area, east of the Northern Tanzanian Rift Valley, with an elevation ranging between $1746 \mathrm{~m}$ and $2037 \mathrm{~m}$. The geology is from volcanic origin and the soils have evolved to loamy clay andosols on the upper slopes, and to the typical swelling clay vertisols in the lower topographic swales. The mean annual rainfall (MAR) ranges from $800 \mathrm{~mm}$ in the lower areas to $860 \mathrm{~mm}$ for the higher areas and was obtained from the global "CHELSA" dataset (Karger et al., 2017). The area has a typical bimodal wet season, with a short peak that occurs from November to December and a long peak between February and May, and one long dry season from June to October (Prins \& Loth, 1988). Local and global climatic phenomena such as the El Nino Southern Oscillation and the Indian Ocean Dipole interlink to create a high interannual variation wherein the short rains can fail (droughts) or connect to the long rains (wet) (Nicholson, 1996). The natural vegetation is mostly an elevation-defined transition between savanna bushland and afro-montane rainforest. The landscape in many areas is characterized by severe surface denudation in open grazing land with notable rill and gully erosion by overland flow (Figure $1 b)$.

The communities are predominantly Maasai and have a long history of assimilation and reciprocal influencing with other ethnic groups such as the waArusha and waMeru. Livelihoods in these communities continue to transition from nomadic pastoralism to sedentary agro-pastoralism driven by factors such as population growth, social and environmental human displacement. While traditional customs have gradually lost importance, they still exist, sometimes assimilated within local governance structures, or in parallel with formal governance. Much village land is still set aside for communal grazing, however, during transition to agro-pastoralism, large areas of land have been entrained into different ownership processes, and used for mixed agriculture. The rights to these lands mostly belong to the 'original' Maasai people although some of these plots are also being leased to farmers from other regions in Tanzania who pay for their tenure in crop-shares. Both processes have resulted in a conversion of semi-natural grazing lands to cropland. The dominant cropping system is intercropping of maize with common beans. However, there are other crops grown in the area such as wheat and horticultural products. These croplands areas are mostly located in the upper slopes of the landscape, while the grazing lands are mostly located in the lower areas and topographic swales.

$<<$ Insert Figure $2>>$

Figure 2: Emaerete catchment (a) broad land cover and (b) topography showing areas designated for agriculture (grey outline) where remainder is open land utilized for common grazing. Note areas of severe gully erosion and surface denudation.

\subsection{Drone survey and geospatial analysis}

To develop a topographic digital surface model (DSM) of the study area using photogrammetry, a drone photographic survey was undertaken using a Phantom Potensic T25 drone equipped with internal GPS and a 1080p GPS digital RGB camera with an optimized $120^{\circ}$ wide-angle lens. The flightpath was set to take photographs from an altitude of $400 \mathrm{~m}$, reduced to $150 \mathrm{~m}$ over hill top areas that were obscured by cloud cover. The flightpath was set so that images had greater than $65 \%$ overlap. Twelve ground-based GPS reference points were made along the boundaries of the designated area to permit vertical alignment of relative elevations derived from the drone survey. A Digital Elevation Model (DEM) was created using photogrammetric routines within Agisoft Metashape whereby building and tree interference was removed from the DSM by excluding points that had a steep $\left(>80^{\circ}\right)$ angle with adjacent point.

The red, green and blue bands of a compile orthomosaic aerial image of the study area were used as the input for a maximum likelihood classification using the QGIS 3.4 saga tool Supervised Classification for Grids'. Training data were generated through heads up digitisation of that aerial photograph. The output of this 
process successfully differentiated gullies and rills from other forms of ground cover but could not distinguish between the different vegetation communities present within the catchment. This high-resolution mapping of soil erosion features was therefore supplemented with a conventional aerial photograph interpretation exercise carried out at a scale of 1:3000. In addition to the classification of broad land cover types within the study area, cultivated land use was subject to a further level of classification according to the direction of cultivation. This categorisation was undertaken as a simple aerial image interpretation (at a scale 1:500) with discontinuities in land management practices being recorded as separate features (land parcels) within the GIS layer.

The 1m DEM of the site was analysed in QGIS 3.10 to produce a model of potential surface flow, slope aspect and slope degree. In order to simplify subsequent analyses, the aspect of each $1 \mathrm{~m}$ pixel within the elevation model were categorised into one of the 8 cardinal directions (N, NE, E, SE, S, SW, W, NW) These DEM derivatives were used as inputs in the following analyses. Mean slope degree and modal aspect were calculated for each parcel of cultivated land identified in the aerial photograph interpretation using QGis's Zonal statistics tool. The direction of cultivation recorded in the aerial imagery interpretation was then compared with the modal aspect for each land use parcel and the relationship between the two described using these qualitative classes: cultivation along contours, cultivation with slope and intermediate cultivation - where the direction of cultivation had no strong relationship the aspect of the field. The modelled surface flow was used for two purposes, firstly to create a Strahler ordered model of potential overland flow convergence within the study area, and secondly to select those bare ground (interpreted as eroded) pixels within the landscape that were probably generated by surface flow i.e. rills and gully features (in the main visible in high resolution photography). The selected pixels were then converted into point data and their density expressed as area $\left(\mathrm{m}^{2}\right)$ per $\mathrm{m}^{2}$ calculated to derive an independent index of observed erosion feature density.

\subsection{Community consultation and engagement}

The village level is spatially the lowest statutory administrative unit in Tanzania and as such, provides two key advantages for our participatory research approach. First; at this level, local environmental knowledge and understanding of farm-specific soil condition, water run-off and seasonal micro-climate is the most finely nuanced and second; planning and implementation of potential institutional and community responses has the highest chance of success because those directly affected by the problems are also directly engaged in designing workable solutions (Blake et al. 2018). Previous co-design work with these communities has shown that strong participatory engagement and knowledge exchange has delivered better understanding of the impact of social, cultural and economic drivers on soil management challenges. This approach underpins the model of engagement discussed in this paper. Participatory approaches enable affected stakeholders to jointly define the scale and nature of the problem, find common ground in determining impacts and identify relevant policy mechanisms and levers for reform. Our previous research has demonstrated that good soil management is needed which necessitates farmers and land managers to be empowered to continue to innovate towards sustainable resource conservation. The ambition of participatory research is to catalyse the development of a culture of mutual understanding of potentially competing interests, and willingness to support honest and open dialogue built around shared understanding of the socio-economic and well as the hydrological connectivity of the landscape (Brown, 2002; Moore and Westley, 2011).

Building on previous participatory research carried out with Emaerete community, a workshop was designed to bring the co-produced set of visual materials and associated results back to the community and to use them as a mechanism to explore key elements of local hydrological, biological and socio-economic connectivity in generating soil erosion issues. The workshop was held in Emaerete community, attended by twenty participants from the community and five district government personnel who were further consulted on workshop outcomes. All discussions were conducted in Swahili, with facilitation by Tanzanian members of the research team, and with concurrent translation for English-speaking team members. Discussions were audio recorded, subsequently transcribed and translated into English.

Following a brief introduction on the format of the workshop and the collaborative research activities to be completed, work was structured into two elements: 
1. A short 'report back' and review session providing feedback on the wider 'Jali Ardhi' project research findings to date, (Blake et al., 2018; Rabinovich et al., 2019; Wynants et al., 2020, 2018) and team learning from community experiences regarding erosion mitigation measures taken to date. Measures included demarcated livestock exclusion zones for gully rehabilitation; and community commitments to plant trees and shrubs; reduce vegetation cutting and change livestock grazing patterns.

2. Introduction and discussion of the drone survey aerial photo mosaic (one A0 scale copy for group discussion) and A2 scale copies for ease of handling be individual participants); an infographic tool highlighting soil erosion processes; and a set of previously produced local erosion impact photographs.

These visual tools were used by both the research team and participants in multiple ways to illuminate discussion points and trace hydrological connectivity within the landscape. Using visual methods such as photographs and the DEM model has the distinct advantage of creating a shared frame of reference and intuitive understanding despite the complex and abstract nature of the information. Visual methods using photographs and images are particularly helpful in supporting a process of joint learning, negotiation and reflection, around which soil erosion issues and associated connectivity can be identified. Image-elicitation is based on the use of one or a series of photographs or other images in a participatory research context, in order to reach a deeper understanding of something (Harper, 2002). Image-elicitation can stimulate empathetic understanding and draw out connections that might not otherwise be made. In this multi-stakeholder context, discussion alone faces the challenge of creating a trusting environment between participants from widely differing backgrounds and philosophical standpoints, and there is a need to 'bridge the gap'. Image-elicitation techniques can overcome these differences by offering a shared frame of reference (a composite image of the wider context, or of a particular issue, for example) on which to build trust and through which deeper insights can emerge than would otherwise be achieved through discussion alone (Collier and Collier, 1986).

\section{Results}

\subsection{Topography and land cover}

Derived land cover classes (Figure 3a) were broadly spread across cultivated plots (26\%), open pastoral land (30\%) including homestead farm areas with sporadic tree and shrub cover and exposed soil surfaces in and around village buildings. Areas with patchy grass and rough shrub cover, often with intermittent soil loss and vegetation disturbance due to erosion, were classed as scrub (10\%). Areas of notable bare ground were observed in the severely eroded mid to lower slope region (Figure 4) that receives much of the concentrated overland flow from the hillslopes above.

$<<$ INSERT FIGURE $3>>$

Figure 3: (a) land cover classification and (b) derived mean slope for cultivated plots

$<<$ Insert Figure $4>>$

Figure 4: Severely degraded pastoral land in the mid to lower region of the catchment (photos Carey Marks/University of Plymouth, taken March 2017)

The cultivated plots occupied the east and southeastern side of the catchment upland zone and hence represent potential overland flow contribution areas to the mid and lower slope gullied zones. The group of cultivated plots to the east of the system are the most recently converted (from open grazing to cultivation) land (ca 1-3 years prior to survey) with boundaries set to shallow ditches and bunds akin to 'slow-forming' terrace approaches (Chapagain and Raizada, 2017; Dercon et al., 2003). Vegetation along these boundaries was largely immature grasses. The cultivated plots to the south were more established (over 7 years) with notable establishment of edge-of-plot bunds and mature vegetation along boundaries. In both areas of cultivation, uppermost plots showed steeper slopes (Figure $3 \mathrm{~b}$ ) graduating to more gentle slopes toward and on the open pastoral land.

The cultivated land plots are interconnected with unmetalled trackways commonly used to drive livestock and for pedestrian and motorbike access. All tracks are incised to varying degrees with notable incision 
on downslope reaches of tracks from upper cultivated plots. Severe erosion of pastoral land originates from apparent overland flow spill over and concentration from track in centre west of the study area (Figure $3 \mathrm{~b}$ ). Severe gully erosion has resulted in upslope relocation of the track on more than one occasion.

\subsection{Structural connectivity framework and observed erosion}

Comparison of potential flow pathways (grey convergence lines, Figure 5) and observed density of rills (whitegrey-black shaded plots in Figure 5) reveal a disconnect in potential and actual development of rill erosion in some plots. Plots coloured white have a low $\left(<0.0005 \mathrm{~m}^{2} \mathrm{~m}^{-2}\right)$ density of rill features observed in the drone survey and there are several notable examples where the topography-driven model predicts flow convergence but no rill erosion features were observed (e.g. northeastern sector, labelled A, Figure 5). Equally, however, there are plots where topography predicts flow convergence which correlated with observations of high-density rill erosion $\left(>0.007 \mathrm{~m}^{2} \mathrm{~m}^{-2}\right)$ (e.g. south eastern sector, area B, Figure 5). Herein there is a notable strip plot showing no erosion features that had apparently been cultivated shortly before the drone survey (see Figure 2a) highlighting potential limitation in the approach with respect to cultivation duration and timing prior to survey. Area $\mathrm{C}$ is notable again for lack of erosion features given potential convergence line density wherein these fields also have limited potential for overland flow run-on given track along upper slope. These areas can be compared to area $\mathrm{E}$ in the open pastoral land where severe erosion was observed, linked to overspill from the track (Figure 4). In comparison to area B, cultivated area D is notable for lack of erosion features given potential for higher order flow convergence routing wherein observational evidence of crop growth indicates potential rill features have not been cultivated out in this instance. It is also noteworthy that the area upslope of these plots remain under semi-natural vegetation cover compared to area $\mathrm{B}$ and that there is no major difference between area D and B in terms of slope angles (Figure 3b). In the more recently converted plots of area $\mathrm{B}$, ca $90 \%$ of the area with potential for flow convergence showed moderate or high density of rill erosion features. In area D, the established agricultural plots, ca $40 \%$ of the area with potential for flow convergence showed moderate rill erosion density.

$<<$ INSERT FIGURE $5>>$

Figure 5: Potential overland flow convergence pathways, major trackways and summary first order observed rill density in cultivated plots.

\subsection{Process connectivity framework and observed erosion}

In terms of process connectivity overland flow enhancement factors, on-the-ground measures of soil infiltration capacity and soil erodibility (aggregate stability) across the different agricultural plots was beyond the scope of this drone survey-based study. We hypothesised, however, that at a higher level, correlation of plot cultivation direction with high density of rill erosion could be illustrative of cultivation controls on potential overland flow generation in the context of process connectivity concepts that encompass impacts on overland flow generation and slope length.

$<<<$ Insert Figure $6>>>$

Figure 6: Aerial photographs of key illustrative zones showing field boundaries, cropping practice and incidence of rill erosion.

Zones of different time since plot establishment, configuration and within plot practice showed different degrees of rill density and network development (Figure 6). In zone B, where the greatest density of rill erosion was observed, there were two main rill networks (labelled B1, B2, Figure 7) connecting upper slope to lower and discharging onto the main track running E-WSW which ultimately spills across the pastoral land at E. The agricultural plots in B1 are oriented across slope so boundaries traverse any potential flow lines in accord with local 'good practice' but cultivation lines within the plots are largely in the direction of slope (indicated by amber and red arrows, Figure 7), with the exception of the lowermost plots. On top of that, the higher plots are also developed on very steep slopes $\left(>12^{\circ}\right)$. In zone B2, again the plots themselves are largely and appropriately orientated across the slope but within plots, there is a mosaic of cultivation 
directions. The rill network on this slope is well developed and crosses all cultivated plots connecting them to the main track way. It is also important to note that the slope length on these plots is also longer.

$<<$ INSERT FIGURE $7>>$

Figure 7: Comparison of first order rill density data and orientation of cultivation with respect to slope

Zones A and D contrast with the situation of zone B. Both zones A and D show more moderate observation of rill density (Figure 6). In zone A, the plots are contoured around a valley head. Plots to the northern side have crop lines contoured with plot boundaries (green arrows, Figure 7) and little evidence of rill erosion. To the southern side, crop lines show some alignment to slope (amber arrows, Figure 7) and there is moderate rill erosion in the lower plots (Figure 6). In Zone D, plot boundaries are more exactly contoured to topography than zone B (Figure 6) and there is only one incidence of cultivation lines being with the slope, the remainder being intermediate or contoured. Rills in this area do not display the same level of development and connectivity as zone B. Zone C offers a different scenario where while cropping lines are contoured, moderate rill erosion was determined (Figure 7) and apparently concentrated along plot boundaries before overtopping edge-of-field bunds (Figure 6). The extensive erosion of gentle to moderately sloped pastoral land, zone E (Figure 6), occurred at the outlet of the track fed by extensive rill erosion in zone B with some contribution from zone $\mathrm{C}$.

\subsection{Infographic tool for dissemination of connectivity concepts}

To support dissemination of connectivity concepts an infographic tool (Figure 8) was developed based on a generic narrative of the consequences of land conversion/grazing on soil vegetative cover and soil surface degradation. The centre part of the infographic focusses on reduced infiltration due to soil exposure and reduced infiltration linked to rain splash, aggregate breakdown with loss of soil organic matter and surface crusting. The wider narrative of the poster was designed to set the landscape in context, showing the destructive narrative of the erosion unfolding from the top, to the bottom of the image. The tracks and pathways dissect the landscape, showing livestock and human traffic aggravating the initial stream channel incisions - and the structural connectivity, linking the upslope disturbance to downslope challenges - and inevitable result of enhanced overland flow.

We chose to create a visual style that would resonate culturally both within the Western and sub-Saharan diaspora. By developing a series of graphic devices, recognisable local iconography, a bright colour palette, and lastly an abstraction of reducing the three-dimensional scenario into a two-dimensional illustration - the attempted result was to create an eye-catching and visually pleasing poster that encouraged interaction and discussion with the researchers and stakeholders alike.

$<<$ INSERT FIGURE $8>>$

Figure 8: Infographic poster designed to explain structural and process connectivity concepts (see text for explanation).

\subsection{Local Environmental Knowledge}

The DEM image generated considerable interest amongst participants. The first step was to orientate the image to local landmarks, to enable those present to identify their own land on the DEM and situate their understanding of the real world three-dimensional landscape within the context of the two dimensional aerial view. Once done, participants used the infographic tool to begin relating their understanding of water flow across their own land, and its associated connection to gullying downslope. This was the first time that local participants could see 'from above' how the complexity of landscape topography played a critical role in whether specific mitigation actions would have the planned effect:

VLG1: In order to fill gullies and look as what we see from the map, we have to plant grasses as it looks down there. This erosion occurs because when the rainwater flows from the upslope it lacks barriers which protect soil from being washed away. So now as the water flows downslope it erodes soil and leave cracks on land surface. All we have to do is plant grasses and trees. 
Although initial discussions centred primarily on how hydrological processes had created rapid overland flow leading to severe erosion and gullying downslope; the focus rapidly shifted towards the physical drivers (lack of effective terracing in upland farms to slow overland flow; lack of trees and vegetation upslope) and associated socio-economic drivers (lack of conservation agriculture knowledge, skills or resources; lack of compliance) as this participant notes:

VLG8: Some of people living uphill there haven't terraced their farms and when it rains water flows through their farms till down here. Facilitator: Why is it that some haven't terraced their farms. Have they not been told or it's just that they don't want? VLG4: It's because of ignorance because everyone has got their own knowledge and understanding. You can find someone lacks even the basic knowledge of doing something in order to prevent soil erosion.

Further discussion highlighted a particular issue on land outside of private ownership, where less effort was made on soil erosion mitigation, and where water was directed towards, to avoid eroding private land. This resulted in faster flow along cattle trackways and paths which were located on common areas. In order to deal with this specific issue, participants identified areas on the map which could be zoned as priority areas to plant trees and shrubs in order to mitigate and slow hydrological flow. The DEM played a critical role in enabling participants to identify the areas for actions likely to have most impact in slowing flow based on their overview of the topography; and supported a much more focussed debate regarding the specific actions (tree-planting; terracing; education) needed to suit the differing soil types in each area:

VLG6: First of all, the places you see are fields that people grow crops. Although people farm, there is a difference in soil between one zone and another. Where you see there is erosion is the newly cultivated farming area and the other side which is uneroded it's uncultivated area. And areas you see as eroded are cultivated areas. Erosion takes place downstream there. But what causes erosion downstream is the difference in soil between down here and up there. Therefore, as water flows from upstream it doesn't erode as it does down here.

Using the DEM, participants also reflected on the relative success of the demonstration plots set up with the community during the original Jali Ardhi project. These areas highlighted the close coupling between institutional factors, such as the commitment of village leadership to maintain these areas as livestock exclusion zones. As a result of that commitment, gullies in the excluded zones had begun to show significant vegetation growth, with the resulting reduction in hydrological flow across this lower-level topography, as this participant noted:

VLG2: Another lesson, you might for example set aside an area for 3 years without livestock getting in. [...] For example, down there you can see we have set an area and prevent cattle from getting in and we have seen changes as gullies are now filling up. The best practice therefore is to set an area and leave it for a while without allowing cattle in so as to allow grasses grow and reduce speed of water flow.

The community-led outcome of this workshop was a commitment to deliver a tree and shrub planting programme, with specific species and planting locations selected by community members. In order to facilitate this next step, a community tree committee was set up, led by the Village Leader, with externally-provided practical training and support in planting techniques and ongoing maintenance. This programme was delivered during the short rainy season in December 2019 to allow the trees to use rain for survival.

\section{Discussion}

\subsection{Translating people-land-water connectivity evidence into targeted mitigation actions}

The modelled flow lines between different catchment areas map indicate direct hydrological connection between severely eroded pastoral land in the mid and lower slope regions of the catchment (Figure 6e) with upslope runoff generation on cultivated plots. Connectivity is enhanced through interconnection of major tracks with natural flow convergence lines, where downslope gully onset was often initiated directly below road channels entering the rangelands (exemplified again in Figure 6e). The whole catchment view of this study is critical in underpinning community-led action. These observations also have important implications 
for track management and planning of runoff drains that can release water and eroded sediment and nutrients back into the fields.

Within plot improvements in soil infiltration capacity to reduce overland flow generation (Kuyah et al., 2019; Nishigaki et al., 2017) is key as is improvement of and aggregate stability, e.g. with amendment by organic matter, to reduce risk of soil capping/crusting (Laker and Nortjé, 2019; Smith et al., 2019) and improve overall soil health (Belayneh et al., 2019; Mesfin et al., 2018). While such within-plot actions can be locally beneficial, analysis in this study has shown that different agricultural plot terraces on the same slope are chained to each other. At the edge of plots, implementation or augmentation of features that can attenuate or slow overland flow to retain soil within the plots are important but poor practice upslope, however, can generate significant overland flow that overwhelms the integrity of downslope plot terraces, even if the latter uses conservation agriculture practices that promote infiltration and good soil health. Herein slope length is a key factor (Gourfi et al., 2018). This is exemplified in zone B1 and B2 where slope length was high ( $<800$ $\mathrm{m}$ ) and the relatively recent conversion of the land with under-developed boundaries meant that attenuation features could not cope with the amounts of overland flow generated. This allowed an extensive and wellconnected rill network to develop and link all plots to each other and the main track (Figure 6b). This was augmented by a large proportion of plots cultivating crop rows in the direction of slope even though the plots themselves, and their boundaries, were aligned across the slope. Off-contour cropping is widely known to enhance rill development (Ayele et al., 2018). In contrast, visual evidence of rilling was markedly lower in the longer established plots (e.g. zone D) where farmers have used contour ploughing and the plot boundaries themselves are more closely aligned with contours. While the upper slope angle is still high, the hilltop steep land has been left in natural vegetation both reducing run-on from the upslope contributing area and effectively reducing the overall length of the slope segment. With the longer-term establishment of plot boundaries there is further resilience to development on connected rill networks due to edge-of-plot barriers that are not overwhelmed by any overland flow that does occur under extreme rainfall conditions. The strong influence of the direction of crop lines is further exemplified by comparison of the two valley sides of Zone A (Figure 6a).

Comparison of the longer-established cultivated plots and recently converted land in this study highlights a problem in the initial phase of slow-forming terraces, as not enough time has passed for the buffers to become effective in stopping flow and the slope gradients to decrease, giving almost free reign to erosive processes. The community picked up the key issue of plot boundary integrity and flow retardation by natural vegetation, wherein suggestions of planting trees and permanent grasses were made. The integration of people, land and water into one connectivity framework exposed a direct chain of cause and effect that can promote cooperative community-led mitigation to stop the downstream propagation of runoff. This is potentially facilitated by the agro-pastoral structure of the community, wherein farmers are both dependent on cropland and on the rangelands for livestock grazing, presenting an opportunity for integrated catchment management.

\subsection{Catalyzing local governance decisions to increase landscape resilience to erosion}

The DEM and orthomosaic aerial photograph provided a unique visualisation of the landscape connectivity for community members who have little formal scientific training and normally have no access to satellite imagery. One of the central aspects underpinning the workshop discussion of hydrological connectivity on the ground was an implicit understanding of the need for effective governance mechanisms (including policy instruments) at both community and District levels, to enable community-led actions to be implemented effectively and, more importantly, consistently. Herein a key incentive (German, 2018) being retention of soil and nutrients within the plot and reducing collective impact on downslope common land. Two specific governance elements were identified by participants: Committed leadership supported by the majority of the community; and effective sanctions for policy non-compliance. Previous co-designed community actions (Blake et al., 2018; Rabinovich et al., 2019) included setting aside (and fencing against livestock) an area of severely eroded and gullied communal grazing land, as a demonstration plot to trial potential erosion mitigation and rehabilitation solutions. The demonstration plot had been established for three years and 
had been significantly expanded by the community without further external support or materials. The effectiveness of this area at slowing water and the speed of revegetation was frequently commented on during the workshop. Critically, the success of these plots (Figure 9) was recognised as being largely a reflection not of their physical design but of the quality of governance processes within this specific community. Despite severe pressure for grazing land, community members (including those who were not directly involved in the previous projects) were prepared to respect the Village Leader's decision to exclude grazing in this area notwithstanding the resulting personal economic costs (loss of grazing). Success rested on short term gain for a small number of community members being deferred for longer-term gain for the wider community.

The connection between good governance mechanisms and mitigation measures to slow water in high risk areas reflects the temporal and spatial challenges of taking proximal actions to achieve distal benefits (Wynants et al., 2019). Land management actions need to be taken upslope and regularly maintained, at cost to individual land owners and users, but the benefits are largely experienced downslope and across relatively longer timeframes. Despite these challenges, this research demonstrates that using images and other visual tools supports communities to visualise actions, and associated changes in three dimensions; and facilitates abstraction of impacts beyond individual costs, to reveal wider societal benefits.

$<<<$ INSERT FIGURE $9>>>$

Figure 9: evidence of recovery following livestock exclusion (comparing March 2017 and November 2019)

\section{Conclusion}

While soil erosion processes are complex and multifaceted, co-design of land management policy tailored to the needs of specific communities can be achieved through participatory engagement where scientists and the community work together to identify evidence of the problem, evaluate the drivers and share knowledge to inform actions. This contribution demonstrates how communication of land degradation process knowledge, through an established interdisciplinary participatory approach has supported community-led change in land management in an East African agro-pastoral community. High resolution aerial photography coupled with flow connectivity modelling and geospatial analysis demonstrated the importance of upslope overland flow generation and routing from recently converted cultivated land to downslope grazing land where severe erosion is observed and formerly believed to be wholly caused by overgrazing. Herein community adaptability that is needed to cope with the challenges brought by dynamic people-land-water connectivity can be undermined by a lack of ability to respond due to a lack of 'slack' in their systems caused by erosion of their resources and their options. This study demonstrates that such barriers can be overcome wherein impact from research evidence bases was realized though a knowledge exchange workshop with community leaders, livestock owners, farmers and District Council officials. Key outcomes were the formation of a tree planting committee, implementation of a targeted planting programme of 200 trees and shrubs in hydrologically vulnerably hot spots, new grazing management regimes and commitment to a longer-term community land management plan. The study demonstrates the critical importance of integrated upstream/upslope and downstream/downslope thinking when tackling complex soil erosion challenges.

\section{Acknowledgements:}

The research team are indebted to the commitment and warm support of the community in Emaerete village. The research was supported by Research England 'QR' Global Challenges Research Funds allocated by the University of Plymouth [Ardhi na Kujifunza (Land and Learning] building on UK Natural Environment Research Council Grant NE/R009309/1 and Research Council UK Global Challenges Research Fund (GCRF) grant NE/P015603/1. The study represents a contribution to the joint UN FAO/IAEA Coordinated Research Projects (CRP) "D15017: Nuclear Techniques for a Better Understanding of the Impact of Climate Change on Soil Erosion in Upland Agro-ecosystems" and "D1.50.18: 'Multiple Isotope Fingerprints to Identify Sources and Transport of Agro- Contaminants" ".

\section{Conflict of Interest Statement}

The authors have no conflict of interest to declare. 


\section{Statement of contribution of authors}

All authors are active contributors to intellectual content. The manuscript concept was conceived by WB who led the drafting of the manuscript and analysis and interpretation of data. CK led the acquisition and interpretation of the social science data and contributed to the structure and drafting of the manuscript. MW contributed analysis and interpretation of geospatial data, and structure and drafting of the manuscript. AP co-led acquisition of social science data and contributed to socio-cultural interpretations and drafting of the manuscript. SL designed and undertook specialist geospatial data analysis, interpretation and visualization and drafting of the manuscript. JL, EN and AP made substantial contributions to acquisition of data through drone survey design and implementation plus data interpretation within post-processing of DEM. MN contributed intellectual design of stakeholder engagement process to acquire social science data. CM conceived and delivered infographic design and intellectual integration with science mission. DG, KM, LM and PN contributed to drafting through critical revision of manuscript intellectual content.

\section{REFERENCES}

Ayele, G.K., Addisie, M.B., Langendoen, E.J., Tegegne, N.H., Tilahun, S.A., Moges, M.A., Nicholson, C.F., Steenhuis, T.S., 2018. Evaluating erosion control practices in an actively gullying watershed in the highlands of Ethiopia. Earth Surf. Process. Landforms 43, 2835-2843. https://doi.org/10.1002/esp.4436

Belayneh, M., Yirgu, T., Tsegaye, D., 2019. Effects of soil and water conservation practices on soil physicochemical properties in Gumara watershed, Upper Blue Nile Basin, Ethiopia. Ecol. Process. 8. https://doi.org/10.1186/s13717019-0188-2

Berkes, F., Folke, C., Colding, J., 2000. Linking social and ecological systems: management practices and social mechanisms for building resilience vol 1.

Blake, W., Rabinovich, A., Wynants, M., Kelly, C., Nasseri, M., Ngondya, I., Patrick, A., Mtei, K., Munishi, L., Boeckx, P., Navas, A., Smith, H., Gilvear, D., Wilson, G., Roberts, N., Ndakidemi, P., 2018. Soil erosion in East Africa: an interdisciplinary approach to realising pastoral land management change. Environ. Res. Lett. https://doi.org/10.1088/1748-9326/aaea8b

Bracken, L.J., Wainwright, J., Ali, G.A., Tetzlaff, D., Smith, M.W., Reaney, S.M., Roy, A.G., 2013. Concepts of hydrological connectivity: Research approaches, pathways and future agendas. Earth-Science Rev. 119, 17-34. https://doi.org/10.1016/j.earscirev.2013.02.001

Brown, K., 2002. Innovations for conservation and development. Geogr. J. 168, 6-17. https://doi.org/10.1111/14754959.00034

Chapagain, T., Raizada, M.N., 2017. Agronomic Challenges and Opportunities for Smallholder Terrace Agriculture in Developing Countries. Front. Plant Sci. 8, 331. https://doi.org/10.3389/fpls.2017.00331

Cobo, J.G., Dercon, G., Cadisch, G., 2010. Nutrient balances in African land use systems across different spatial scales: A review of approaches, challenges and progress. Agric. Ecosyst. Environ. https://doi.org/10.1016/j.agee.2009.11.00

Collier, J.J., Collier, M., 1986. Visual anthropology: Photography as a research method (revised and expanded edition). University of New Mexico Press.

Dercon, G., Deckers, J., Govers, G., Poesen, J., Sánchez, H., Vanegas, R., Ramírez, M., Loaiza, G., 2003. Spatial variability in soil properties on slow-forming terraces in the Andes region of Ecuador. Soil Tillage Res. 72, 31-41. https://doi.org/10.1016/S0167-1987(03)00049-7

FAO, 2019. Let's \#StopSoilErosion to ensure a food secure future | FAO Stories | Food and Agriculture Organization of the United Nations [WWW Document]. URL http://www.fao.org/fao-stories/article/en/c/1192794/ (accessed 3.23.20).

German, L., 2018. Catalyzing self-governance: Addressing multi-faceted collective action dilemmas in densely settled agrarian landscapes. Int. J. Commons 12, 217-250. https://doi.org/10.18352/ijc.852 
Gourfi, A., Daoudi, L., Shi, Z., 2018. The assessment of soil erosion risk, sediment yield and their controlling factors on a large scale: Example of Morocco. J. African Earth Sci. 147, 281-299. https://doi.org/10.1016/j.jafrearsci.2018.06.0

Harper, D., 2002. Talking about pictures: A case for photo elicitation. Vis. Stud. 17, 13-26. https://doi.org/10.1080/147258602

Hiemstra-van der Horst, G., Hovorka, A.J., 2009. Fuelwood: The "other" renewable energy source for Africa? Biomass and Bioenergy 33, 1605-1616. https://doi.org/10.1016/j.biombioe.2009.08.007

Homewood, K., Coast, E., Thompson, M., 2004. In-Migrants and Exclusion in East African Rangelands: Access, Tenure and Conflict. Africa (Lond). 74, 567-610. https://doi.org/10.3366/afr.2004.74.4.567

International Institute of Rural Reconstruction., African Conservation Tillage Network., 2005. Conservation agriculture : a manual for farmers and extension workers in Africa. International Institute of Rural Reconstruction.

Jayne, T.S., Chamberlin, J., Headey, D.D., 2014. Land pressures, the evolution of farming systems, and development strategies in Africa: A synthesis. Food Policy 48, 1-17. https://doi.org/10.1016/j.foodpol.2014.05.014

Kagabo, D.M., Stroosnijder, L., Visser, S.M., Moore, D., 2013. Soil erosion, soil fertility and crop yield on slow-forming terraces in the highlands of Buberuka, Rwanda. Soil Tillage Res. 128, 23-29. https://doi.org/10.1016/j.still.2012

Kassam, A., Friedrich, T., Derpsch, R., 2019. Global spread of Conservation Agriculture. Int. J. Environ. Stud. 76, 29-51. https://doi.org/10.1080/00207233.2018.1494927

Korotayev, A., Zinkina, J., 2015. East Africa in the Malthusian Trap? J. Dev. Soc. 31, 385-420. https://doi.org/10.1177/0169796X15590322

Kuyah, S., Whitney, C.W., Jonsson, M., Sileshi, G.W., Oborn, I., Muthuri, C.W., Luedeling, E., 2019. Agroforestry delivers a win-win solution for ecosystem services in sub-Saharan Africa. A meta-analysis. Agron. Sustain. Dev. 39. https://doi.org/10.1007/s13593-019-0589-8

Laker, M.C., Nortje, G.P., 2019. Review of existing knowledge on soil crusting in South Africa, in: Advances in Agronomy. Academic Press Inc., pp. 189-242. https://doi.org/10.1016/bs.agron.2019.01.002

Lal, R., 2001. Soil degradation by erosion. L. Degrad. Dev. 12, 519-539. https://doi.org/10.1002/ldr.472

Little, P.D., 1996. Pastoralism, biodiversity, and the shaping of savanna landscapes in East Africa. Africa (Lond). 66, 37-51. https://doi.org/10.2307/1161510

Mesfin, S., Taye, G., Desta, Y., Sibhatu, B., Muruts, H., Mohammedbrhan, M., 2018. Short-term effects of bench terraces on selected soil physical and chemical properties: landscape improvement for hillside farming in semi-arid areas of northern Ethiopia. Environ. Earth Sci. 77. https://doi.org/10.1007/s12665-018-7528-x

Moore, M.L., Westley, F., 2011. Surmountable chasms: Networks and social innovation for resilient systems. Ecol. Soc. 16. https://doi.org/10.5751/ES-03812-160105

Nearing, M., Pruski, F.F., O'Neal, M.R., 2004. Expected climate change impacts on soil erosion rates: A review. J. Soil Water Conserv. 59.

Ngecu, W.M., Mathu, E.M., 1999. The El-Nino-triggered landslides and their socioeconomic impact on Kenya. Environ. Geol. 38, 277-284. https://doi.org/10.1007/s002540050425

Nishigaki, T., Sugihara, S., Kilasara, M., Funakawa, S., 2017. Surface Runoff Generation and Soil Loss Under Different Soil and Rainfall Properties in The Uluguru Mountains, Tanzania. L. Degrad. Dev. 28, 283-293. https://doi.org/10.1002/ldr.2499

Odgaard, R., 2002. Scrambling for land in Tanzania: Process of formalisation and legitimisation of land rights. Eur. J. Dev. Res. 14, 71-88. https://doi.org/10.1080/714000434

Oldeman, L.R., 1991. Global Extent of Soil Degradation, ISRIC Bi-Annual Report. 
Pretty, J., 2003. Social Capital and the Collective Management of Resources. Science (80-. ). https://doi.org/10.1126/science.

Pretty, J.N., 1995. Participatory learning for sustainable agriculture. World Dev. 23, 1247-1263. https://doi.org/10.1016/030 750X(95)00046-F

Rabinovich, A., Kelly, C., Wilson, G., Nasseri, M., Ngondya, I., Patrick, A., Blake, W.H., Mtei, K., Munishi, L., Ndakidemi, P., 2019. "We will change whether we want it or not": Soil erosion in Maasai land as a social dilemma and a challenge to community resilience. J. Environ. Psychol. 66. https://doi.org/10.1016/j.jenvp.2019.101365

Reed, M.S., Vella, S., Challies, E., de Vente, J., Frewer, L., Hohenwallner-Ries, D., Huber, T., Neumann, R.K., Oughton, E.A., Sidoli del Ceno, J., van Delden, H., 2017. A theory of participation: What makes stakeholder and public engagement in environmental management work? Restor. Ecol. 1-11. https://doi.org/10.1111/rec.12541

Rufino, M.C., Thornton, P.K., Ng'ang'a, S.K., Mutie, I., Jones, P.G., van Wijk, M.T., Herrero, M., 2013. Transitions in agro-pastoralist systems of East Africa: Impacts on food security and poverty. Agric. Ecosyst. Environ. 179, 215-230. https://doi.org/10.1016/j.agee.2013.08.019

Ruttan, L.M., Borgerhoff Mulder, M., 1999. Are east African pastoralists truly conservationists? Curr. Anthropol. 40, 621-652. https://doi.org/10.1086/300086

Smith, J.D.V., Strauss, J.A., Hardie, A.G., 2019. Effects of long-term grazed crop and pasture systems under no-till on organic matter fractions and selected quality parameters of soil in the Overberg, South Africa. South African J. Plant Soil. https://doi.org/10.1080/02571862.2019.1640298

Vanmaercke, M., Poesen, J., Broeckx, J., Nyssen, J., 2014. Sediment yield in Africa. Earth-Science Rev. 136, 350-368. https://doi.org/10.1016/j.earscirev.2014.06.004

Veldhuis, M.P., Ritchie, M.E., Ogutu, J.O., Morrison, T.A., Beale, C.M., Estes, A.B., Mwakilema, W., Ojwang, G.O., Parr, C.L., Probert, J., Wargute, P.W., Grant Hopcraft, J.C., Olff, H., 2019. Crossboundary human impacts compromise the Serengeti-Mara ecosystem. Science (80-. ). 363, 1424-1428. https://doi.org/10.1126/science.aav0564

Wynants, M., Kelly, C., Mtei, K., Munishi, L., Patrick, A., Rabinovich, A., Nasseri, M., Gilvear, D., Roberts, N., Boeckx, P., Wilson, G., Blake, W.H., Ndakidemi, P., 2019. Drivers of increased soil erosion in East Africa's agro-pastoral systems: changing interactions between the social, economic and natural domains. Reg. Environ. Chang. https://doi.org/10.1007/s10113-019-01520-9

Wynants, M., Millward, G., Patrick, A., Taylor, A., Munishi, L., Mtei, K., Brendonck, L., Gilvear, D., Boeckx, P., Ndakidemi, P., Blake, W.H., 2020. Determining tributary sources of increased sedimentation in East-African Rift Lakes. Sci. Total Environ. 717, 137266. https://doi.org/10.1016/j.scitotenv.2020.137266

Wynants, M., Solomon, H., Ndakidemi, P., Blake, W.H., 2018. Pinpointing areas of increased soil erosion risk following land cover change in the Lake Manyara catchment, Tanzania. Int. J. Appl. Earth Obs. Geoinf. 71, 1-8. https://doi.org/10.1016/j.jag.2018.05.008 


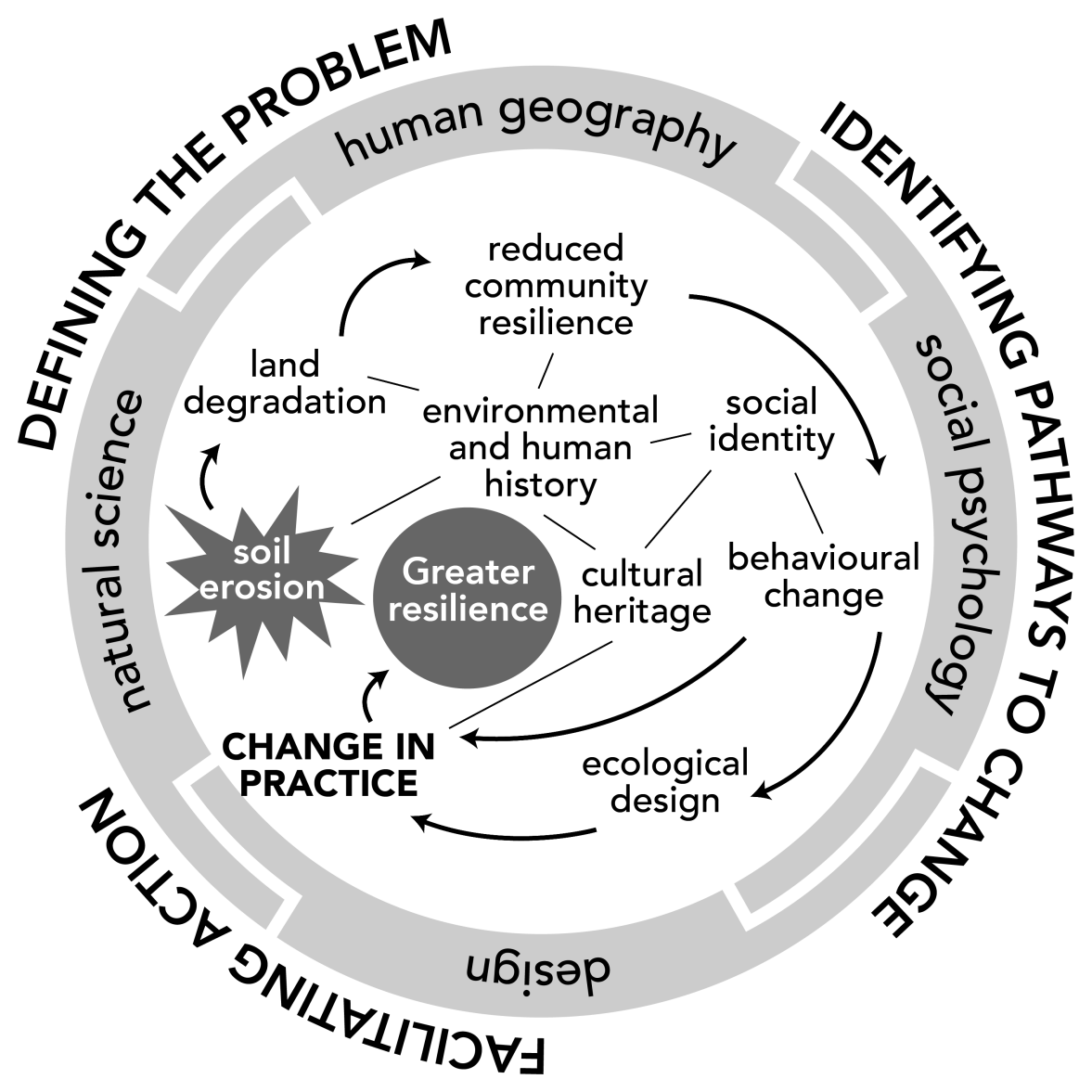



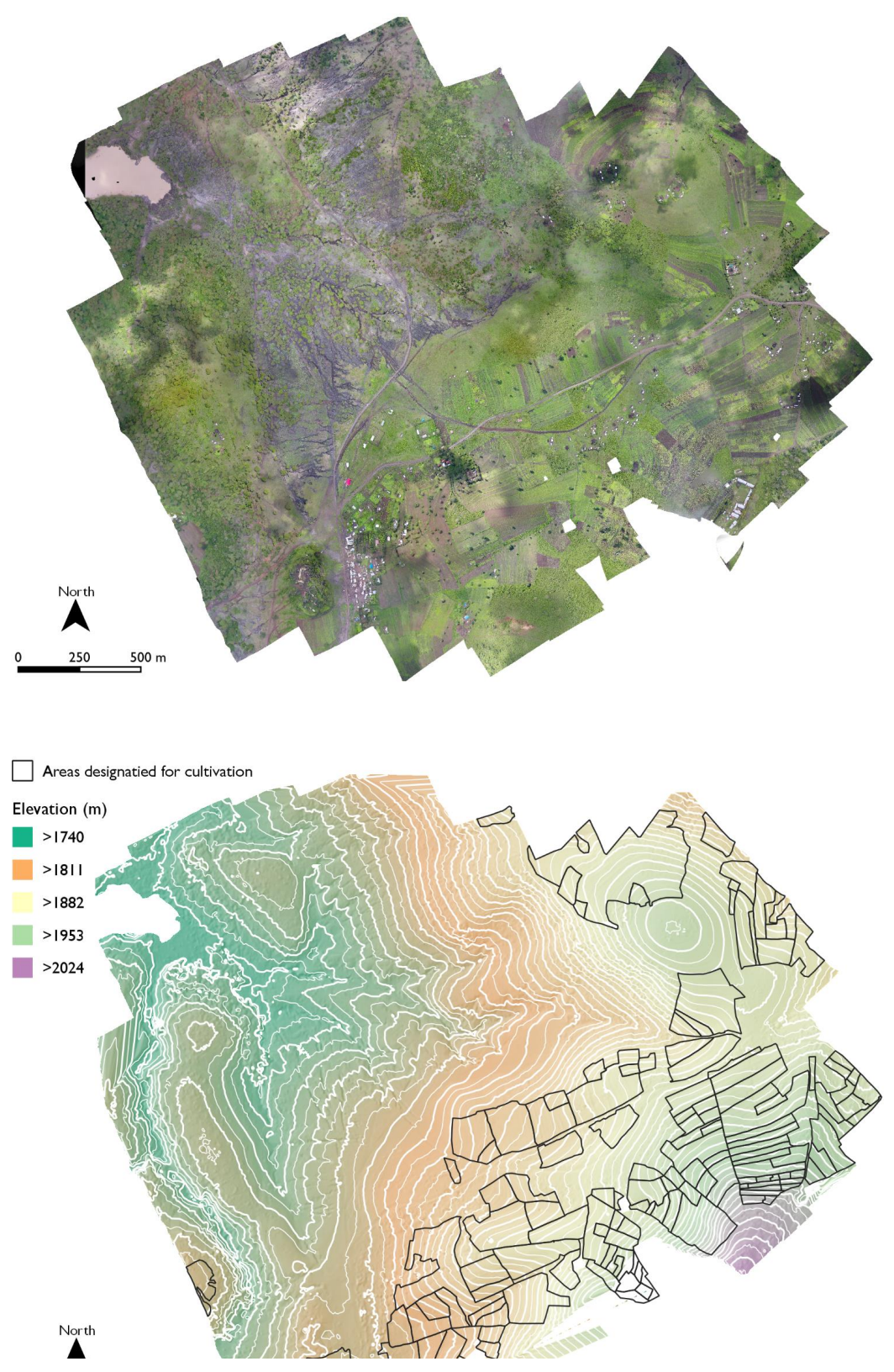

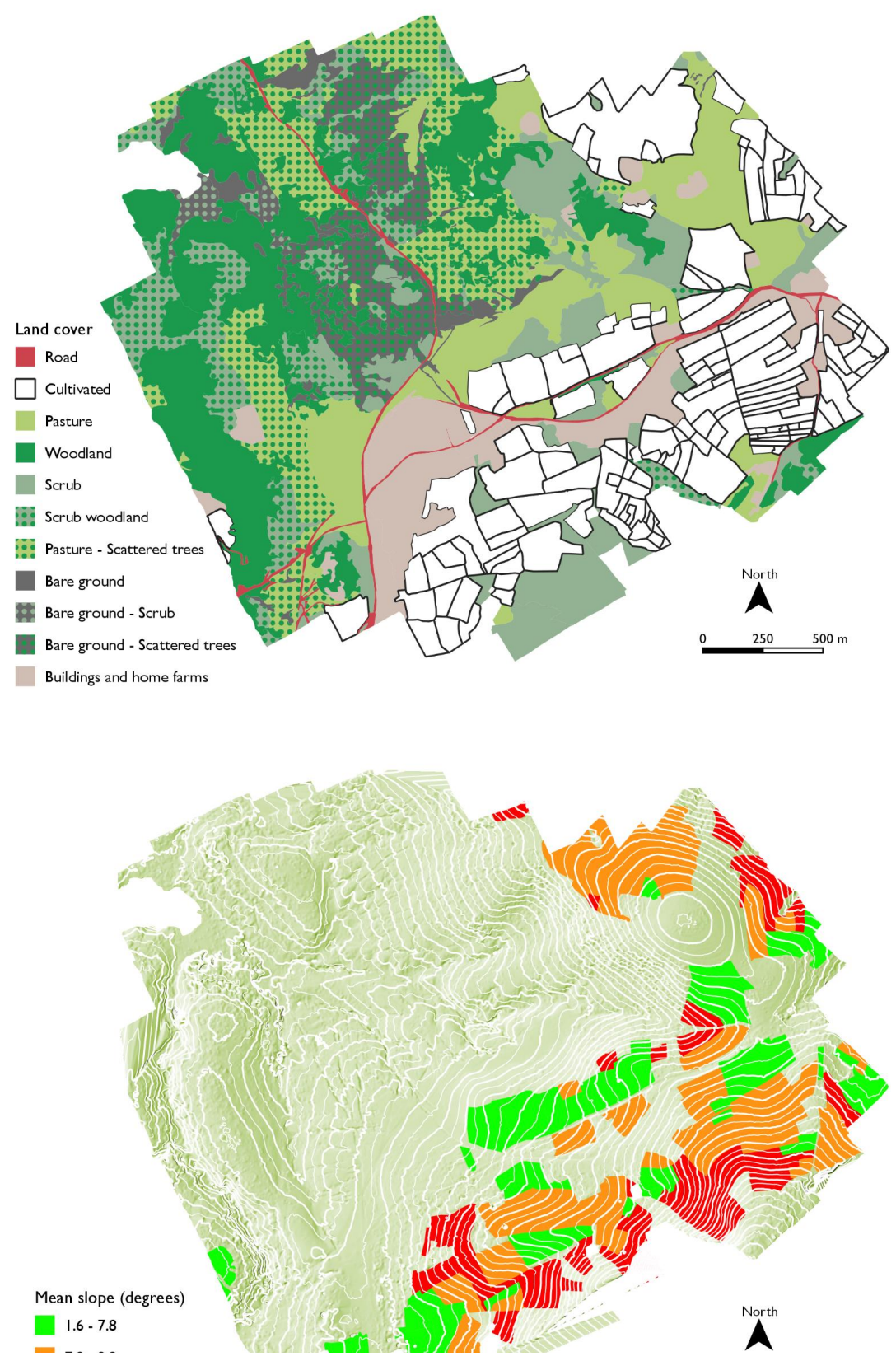

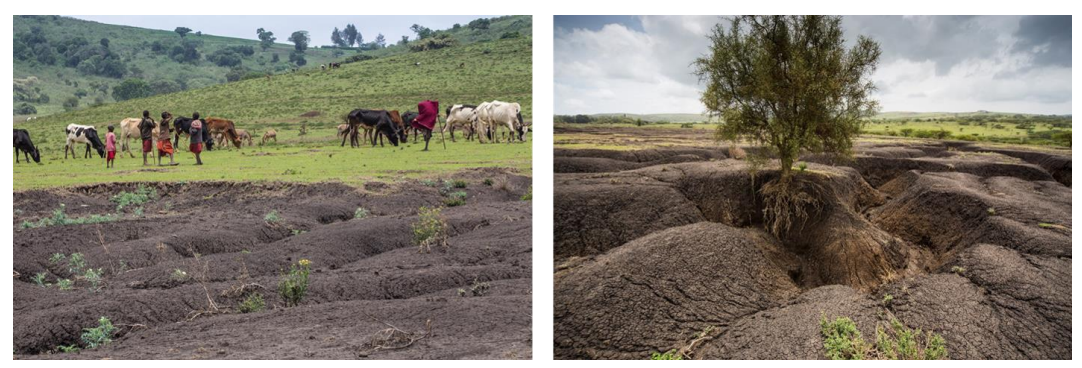


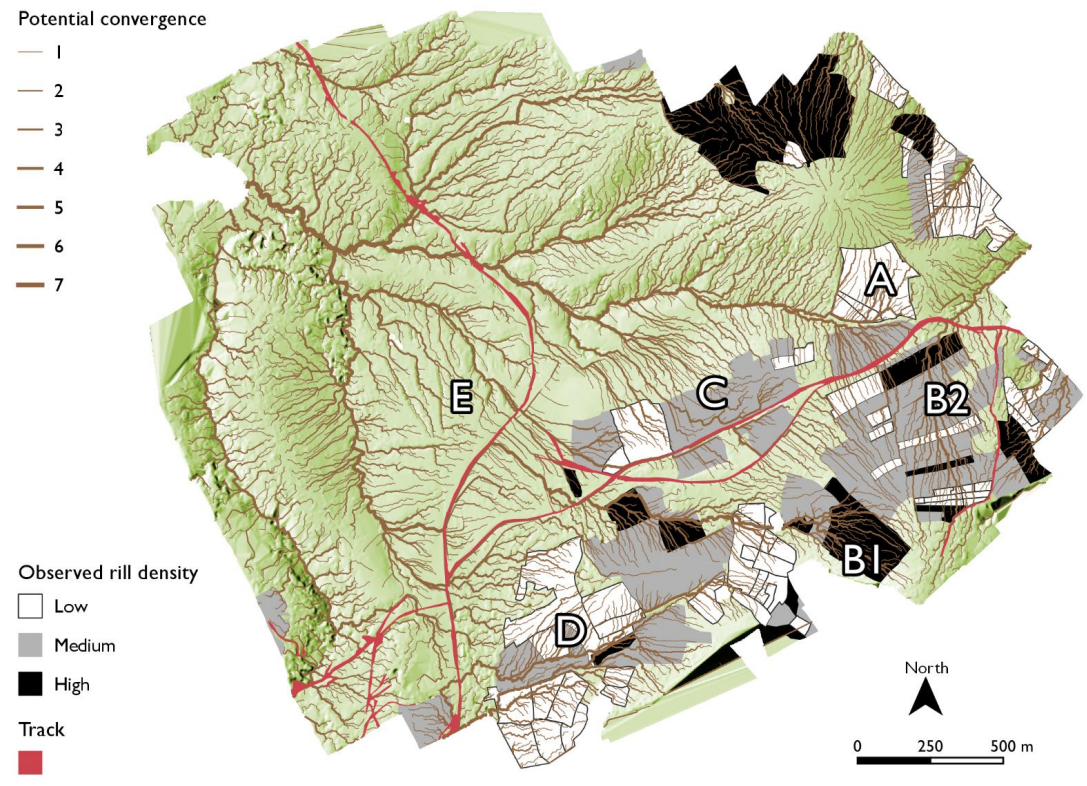



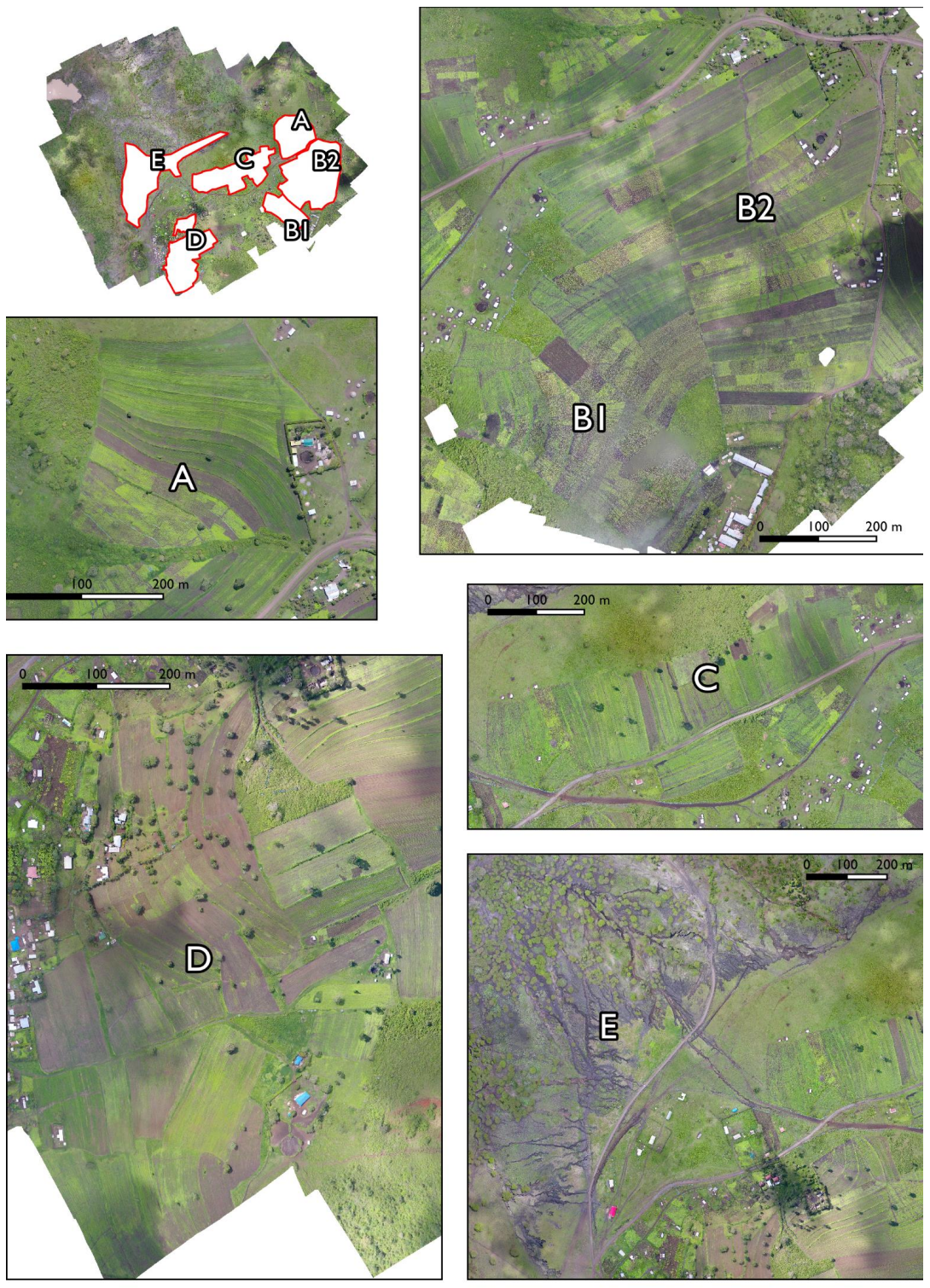


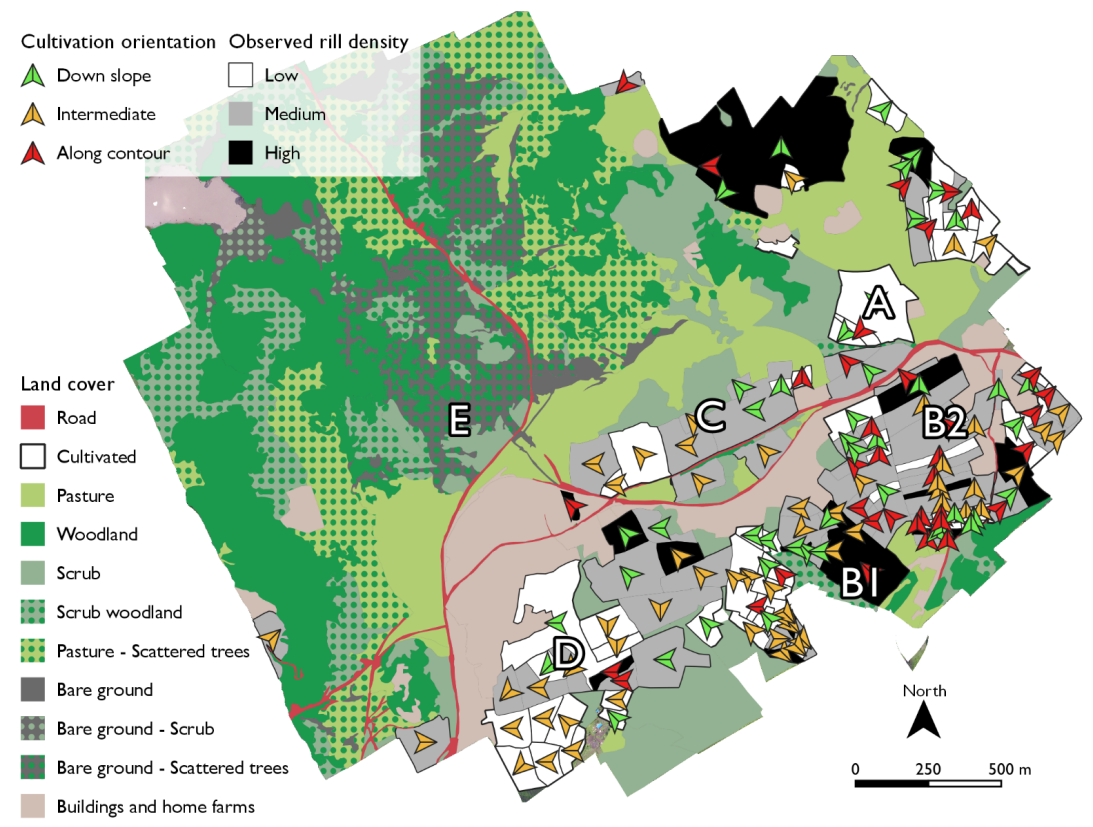



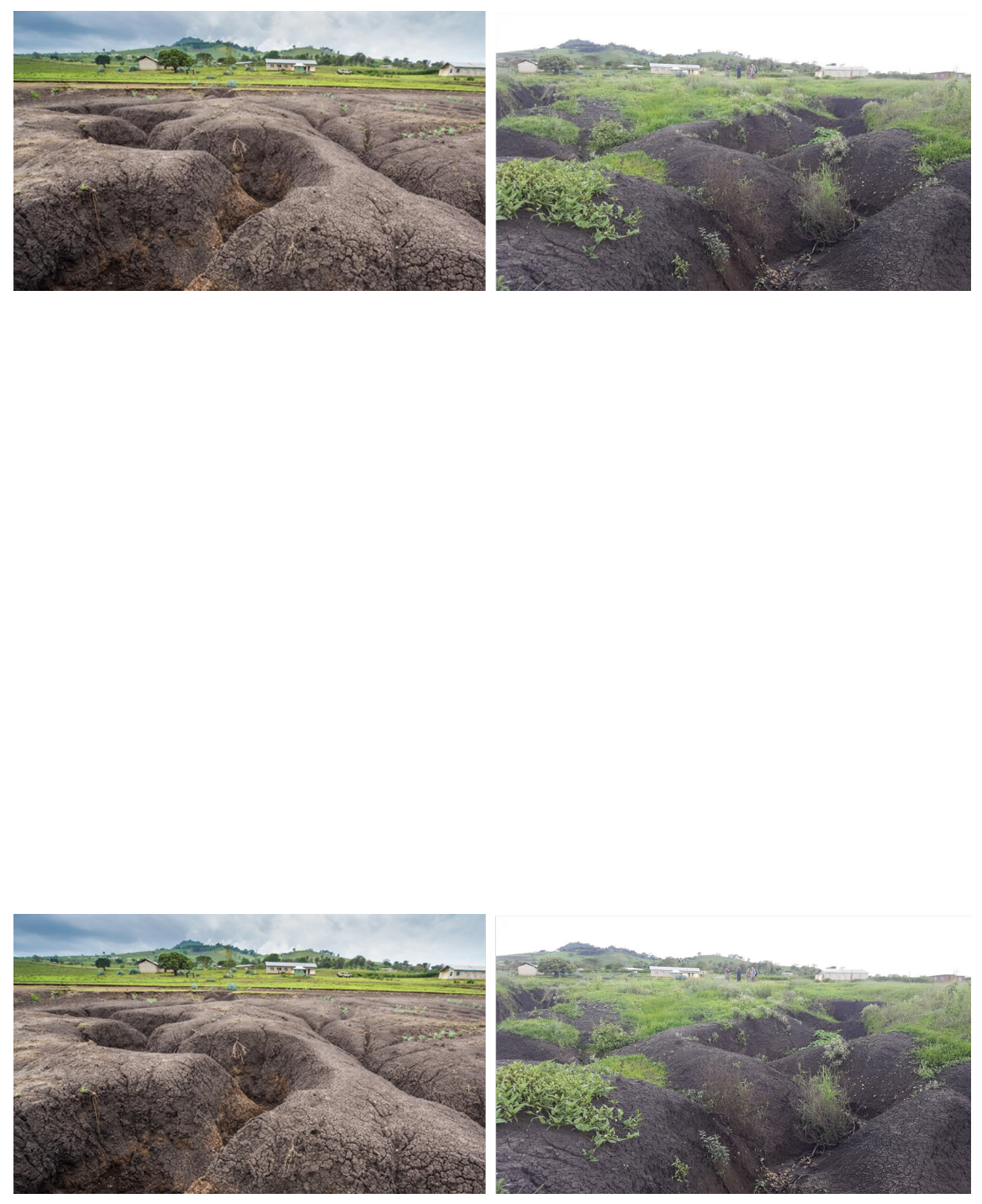